\title{
ESCALERA REYES, JAVIER (Coord.) (2011). Consumir naturaleza. Productos turísticos $y$ espacios protegidos en Andalucía. Sevilla: Aconcagua Libros, 266 pp.
}

Félix Talego Vázquez

Departamento de Antropología Social. Universidad de Sevilla.

Aconcagua es una de esas editoriales que ha resistido el embate de los best sellers, que no sólo son productos de la novela, sino también del ensayo y hasta de la poesía y los trabajos científicos. Desde su nacimiento a mitad de los años noventa ha venido ofreciéndonos, con regularidad, una relación de libros que recogen resultados de investigaciones o estados de la cuestión de temas científicos, especialmente del ámbito jurídico y de las ciencias sociales en Andalucía. Son productos decentes y asequibles, demostrando sus responsables que es viable un proyecto empresarial en el mundo del libro al margen de las "grandes superficies" de la cultura. El libro que presentamos, "Consumir naturaleza. Productos turísticos y espacios protegidos en Andalucía”, coordinado por Javier Escalera Reyes, hace el número 27 de la colección Textos Universitarios y mantiene la tónica de los anteriores en cuanto a su buena factura y acabado.

Se trata de una serie de textos que todos juntos recogen los resultados de una investigación financiada por la Consejería de Innovación, Ciencia y Empresa de la Junta de Andalucía y por los fondos FEDER, con el título "Turismo, recreaciones medioambientales y sostenibilidad en los espacios protegidos andaluces: resiliencia socioecológica, participación social e identificaciones colectivas". La publicación conjunta de los textos en este volumen permite a los autores reunir en un ejemplar los resultados de dicha 
investigación, lo que nos permite hacernos una idea global de la misma y sus resultados. Los autores, investigadores del Grupo de Investigación Social y Acción Participativa (GISAP), abordan en los diferentes capítulos los efectos que el turismo ha tenido y está teniendo en varios territorios andaluces que gozan de alguna figura de protección medioambiental. Se trata, por tanto, de un estudio de los impactos del turismo sobre las sociedades que se asientan en espacios con un singular valor medioambiental, y reconocidos legalmente como espacios protegidos. En todos los casos, según se destaca en el capítulo inicial, los desarrollos turísticos se producen por considerarse los espacios protegidos, o algunos de sus elementos, como "naturales", lo que conduce, paradójicamente, a hacer de ellos "recursos" separados del socioecosistema del que forman parte.

En cada uno de los casos estudiados, los autores se detienen especialmente a considerar las diferentes respuestas que las sociedades locales han ido desarrollando para adaptarse, responder y reorientar el influjo de la actividad turística, demostrando que, en ningún caso, las sociedades locales son meras receptoras pasivas que se someten al incremento de infraestructuras y de turistas en sus territorios. Los autores rechazan el tópico, simplificador, de que el turismo es una actividad por definición negativa, destructiva y degradante para los territorios y sociedades que experimentan un incremento del mismo. Siempre se da algún grado de resiliencia en esos territorios, concebidos desde una perspectiva socioecológica.

El concepto de resiliencia es clave en el libro, hasta el punto de ser el eje vertebrador del análisis de cada caso: los autores estudian cómo los diversos agentes implicados en el territorio desarrollan respuestas tendentes a absorber social y ecológicamente los cambios para mantener, modificadas, las identidades colectivas y la especificidad local, aunque ello se logre en diverso grado, según evidencia la exposición de cada caso. Definen resiliencia como "la capacidad de un socioecosistema para sobreponerse a situaciones de crisis, recomponiéndose creativamente y consiguiendo mantener las características básicas que definen su especificidad". A su vez, el grado de resiliencia de los socioecosistemas - según se apunta en el capítulo introductorio que firma Javier Escalera- es una variable dependiente de, entre otros factores, fundamentalmente, del grado de implicación de la población respecto al territorio. Efectivamente, los sucesivos casos que se presentan vienen a sustentar la tesis que se enuncia al comienzo: el grado en que la actividad turística contribuye a potenciar la implicación de la población local con su territorio es correlativo de procesos de desarrollo sostenible, resiliencia socioecológica y conservación de los valores que justifican la protección de los espacios.

Para cada uno de los espacios protegidos, los autores ofrecen respuestas a las siguientes cuestiones de la investigación: ¿Qué elementos del medio son valorizados para el turismo y por qué agentes?; ¿Qué grado de sintonía existe entre esas valorizaciones y las 
representaciones de las sociedades locales sobre el territorio y los recursos?; ¿Qué actores locales y de qué modo participan en la instrumentación del medio como "recurso" turístico?; ¿Qué papel desempeñan en estos procesos las iniciativas públicas y cuáles las privadas?, y ¿Cómo modifica el turismo las representaciones sobre el entorno?

El capítulo dedicado al Parque Natural Cabo de Gata-Níjar, firmado por J. Antonio Cortés, Victoria Quintero y José María Valcuende, se centra en las visiones discordantes, incluso enfrentadas, sobre el territorio del Parque: la que defiende la Administración y la defendida por los agentes sociales que viven allí, las "poblaciones locales", como las llaman los autores. Un conflicto político que nace de la decisión patrimonializadora de la Administración, que define cuáles son los valores relevantes de aquel espacio y qué se debe salvaguardar, sin que las poblaciones locales hayan sido oídas y convenientemente tomadas en consideración. Según se subraya, el proceso patrimonializador está inspirado por una concepción marcadamente naturalizadora, que minimiza la acción antrópica que ha ido conformando aquellos espacios. Hacen notar, además, que este discurso adopta un carácter elitista, deslegitimando las posiciones locales por desinformadas o atentas a intereses concretos. El trabajo de campo ha permitido a los autores recoger las diversas formas de desencuentro y oposición de las poblaciones locales a la línea política oficial de los rectores del Parque, que queda convenientemente sintetizada en las páginas del artículo. En esencia, según los agentes locales, especialmente aquellos con actividades más dependientes del uso del "espacio natural", la tierra no se destruye o "desnaturaliza" por la actividad humana, sino por su cese, y son ellos y sus predecesores quienes han preservado sus actuales valores ecológicos. Al respecto, y paradójicamente, estos agentes, han llegado a considerar un valor las cualidades ecológicas del territorio, aunque lo interpretan después de otro modo que el ambientalismo oficial.

El siguiente artículo, firmado por Pedro A. Cantero y Estaban Ruiz, versa sobre las posibilidades de la ecogastronomía en el Parque Natural de la Sierra de Aracena y Picos de Aroche. Contiene una semblanza de los paisajes y las gentes de la Sierra, breve pero suculenta, sabor que ya no abandonamos el resto del artículo. El desarrollo argumental es al tiempo propositivo, para convencernos de que es posible revertir la decadencia del medio rural; que una vía para ello es la ecogastronomía, que definen así: una nueva visión de la mesa, que implica a la vez investigación y acción y que responde a un lema axial: bueno, limpio y justo. Bueno para el gusto y para la salud; limpio de productos químicos y de producción no contaminante, sin transportes largos; justo por ser obtenido sin "explotación". A juicio de los autores, la apuesta, para ser efectiva en nuestro tiempo, tiene que articularse con una vuelta a saberes y prácticas campesinas y todo lo que implicaron de sociabilidad, comensalismo y convivialidad, y sumando también un cierto turismo. Este, para no ir en detrimento de la revitalización rural, sino complementarla, tendría que ser huésped agradecido y no el protagonista al que sirven los "naturales del lugar". 
Aunque no se detienen en ello, porque no es su cometido, la propuesta que nos hacen casa con la agroecología y la opción representada por Vía Campesina, o por Slow Food; es decir, llevan al ámbito del comensalismo y la convivialidad esas propuestas políticas, dejándonos un buen sabor de boca, como nos dejan los gazpachos de tomate rosado en su tiempo, que es el verano. Por cierto, que es el tomate rosado el alimento "del terreno" que escogen como "botón de muestra" los autores para argumentar las posibilidades de la ecogastronomía.

María Ángeles Corbacho firma el artículo dedicado al Parque Natural del Estrecho y las transformaciones provocadas por el "turismo del viento" en Tarifa. Es reiterativo en alguno de sus epígrafes y se hace por eso más largo de lo debido. No obstante, está bien escrito y logra articular las posiciones de los distintos actores en torno a las concepciones que tienen del viento y el mar, trayéndonos metáforas e imágenes del mismo recogidas entre las gentes, a un tiempo bellas e ilustrativas de los intereses en liza. A la "gente del campo" y la "gente del mar" que habían habitado el lugar "desde siempre" vinieron a sumarse los "winsurfistas" desde los años setenta. Después han llegado actores institucionales con enorme capacidad de incidir sobre el territorio, como son los promotores del proyecto de ampliación del puerto y los que han llevado a cabo la declaración del Parque del Estrecho. La reconfiguración de la sociedad tarifeña que ha provocado la nueva realidad, directa o indirectamente relacionada con el turismo, es de enorme calado, y la autora analiza una por una las nuevas relaciones de fuerza, tensiones e incluso líneas de fractura. El uso, muchas veces instrumental, que unos y otros actores hacen del par local/foráneos es el hilo conductor de que se sirve María Ángeles para mostrar y explicar las diversas posiciones e intereses presentes.

El caso que se nos presenta después es el del Parque Natural de los Alcornocales. Su autor, Agustín Coca, se centra en cómo ha venido a ser la caza en la comarca y los efectos diversos sobre los sectores sociales y clases que conforman las sociedades locales. Pero, a propósito de la evolución de la actividad cinegética, se nos acerca a otras intervenciones que han sido decisivas en la conformación del territorio del Parque y de las sociedades locales concernidas: la conformación del régimen latifundista, las políticas de repoblaciones forestales emprendidas por las administraciones, las directivas y subvenciones de la UE, la regulación de usos y aprovechamientos del Parque Natural. Desgranando todos estos factores el autor logra hacernos evidente que lo que consideraríamos más "natural", los paisajes del Parque, sus especies animales y vegetales silvestres, así como las prácticas y las estructuras sociales en que se insertan sus gentes, son, enteramente, la resultante de intereses políticos y económicos que han ido imponiéndose sobre otras posibilidades; que todo eso está ahí y ha llegado a ser así como resultado de políticas con enorme capacidad de incidencia sobre el territorio; que venados, muflones y jabalíes son especies tan domesticadas como cabras, ovejas y vacas, y que, por cierto, la proliferación actual 
de aquéllas y detrimento de éstas es resultado de una estrategia en la que los latifundistas han encontrado buenos aliados en las instituciones públicas e, incluso, en ciertos "ecologismos" poco sensibles a la equidad social.

La ornitología, contemplada como turismo ornitológico, es el tema del artículo firmado por Macarena Hernández, sin que se olvide de otras formas de turismo que han ido proliferando junto a aquélla primera. Todas ellas convierten a Doñana en un espacio privilegiado del "turismo de naturaleza". Se nos propone una semblanza desde la situación anterior a su declaración como Parque Nacional del territorio de Doñana, cuando eran tierras de frontera, lacustres y pantanosas. Todo aquel espacio estuvo cerca de ser repoblado de eucaliptos de crecimiento rápido con destino a la cercana fábrica de celulosa que se había instalado por aquellos años en el enclave industrial de Huelva. Los fundadores de la Sociedad Española de Ornitología lo impidieron, con intervenciones estratégicas y decisivas, como las de Francisco Bernis o José Antonio Valverde. Fueron pioneros y artífices señalados de un cambio brusco en la significación y valoración de aquel espacio, que pasó a ser una de las principales reservas de aves de Europa y, por ello, destino predilecto de un cierto turismo especializado, al que se han venido añadiendo otros, de efectos contrapuestos sobre los entornos económicos y sociales del Parque.

El último artículo lo firman Javier Escalera, responsable del grupo de investigación, y Huan Porrah. Trata otra modalidad turística, la termal, cerrando la panorámica de los turismos en Andalucía, que no han pretendido agotar, pues quedan sin abordar el turismo playero o el de los deportes de invierno, por ejemplo. No obstante, la diversidad de problemáticas y efectos que muestra la suma de los capítulos es más que suficiente para avisar a los lectores contra cualquier visión sumaria y unívoca sobre los efectos del turismo. Por si era poca la diversidad de situaciones recogidas en el libro, el último capítulo aborda el conflicto entre bienes comunales y apropiación privada de los recursos, a propósito de los "baños" de Alhama (en el Parque Natural de las Sierras Tejada, Almijara y Alhama), aguas termales de las que se hace uso, que se sepa, desde tiempos romanos. La concepción de diversos actores de aquellas aguas como "recurso turístico" apropiable para beneficio privado choca con usos abiertos y comunales tradicionales, respaldados incluso juridicamente por la titularidad comunal del agua. Bajo esta tensión se esconde, según concluyen los autores, dos opciones alternativas: hacer de la actividad turística un enclave a espaldas de los actores locales, de los que saldrían, en el mejor de los casos, operarios del negocio; o bien aprovechar el agua comunitariamente, conforme a los usos tradicionales, según fórmulas que implicasen a los vecinos y a los turistas. Sólo esta última posibilidad garantizaría la resiliencia de las poblaciones locales.

Así llega el lector al final del texto, abruptamente, pues esperaría un capítulo final de conclusiones, en el que haber volcado el equipo de investigadores las que considera tendencias generales, regularidades, singularidades. En definitiva, las consecuencias más 
relevantes de orden teórico respecto al fenómeno del turismo en sí y sus impactos en espacios naturales protegidos. Ahí, entre otros temas, habríamos esperado el tratamiento de la relación locales-turistas o locales-foráneos, pues en diversos de los artículos había sido destacada y, en ciertos casos, su tratamiento nos resultaba cosificado. Esto y una armonización de textos en cuanto a estilo y extensión, son las cosas que echamos de menos en un libro por lo demás oportuno y pertinente para un abordaje serio del turismo en Andalucía, tantas veces y por tantos presentado casi como un maná. 